\title{
ENERGY EFFICIENCY IN THE AMAZONAS: THE SOLAR ALTERNATIVE
}

\section{Lutegardo Bassal Costa de Freitas ${ }^{1}$, Matheus Cardoso dos Santos ${ }^{2}$, Anderson de Oliveira Castro ${ }^{3}$}

${ }^{1,2}$ Curso de Engenharia Mecânica, Centro Universitário do Norte (UNINORTE). Av. Joaquim Nabuco, 1469, Centro. ManausAmazonas-Brasil. CEP: 69005-290. Fone: +55 (92) 32125000.

${ }^{3}$ Mestre em Engenharia Elétrica pela UFPA, Brasil, Pará.

Email: lutebassal@gmail.com, matheusscardoso22@gmail.com, anderson.castro@uninorte.com.br

Received: June $26^{\text {th }}, 2019$

Accepted: June $27^{\text {th }}, 2019$

Published: September 30th, 2019

Copyright (02016 by authors and Institute of Technology Galileo of Amazon (ITEGAM). This work is licensed under the Creative Commons Attribution International License (CC BY 4.0). https://creativecommons.org/lice nses/by/4.0/

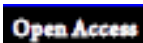

\begin{abstract}
The present article aims to correlate the use of two most used energy sources (thermoelectric and hydroelectric) in the state of Amazonas with the environmental effects from its generation and to elucidate solar energy as a key to energy efficiency and a source of clean and sustainable energy . This work is a bibliographical research with descriptive purposes, presents as delimitation the thermoelectric and hydroelectric power plants of the Amazon. It is possible to observe in the presentation of its results the environmental impacts caused by the generation of electrical energy that are of concern and what short-term measures should be taken. Finally, the final considerations reveal the need to adapt the energy system of the Amazon to the renewable energies, especially solar that presents great potential in the region, but still little explored, such adaptation is already verified in developed countries, taking into account the changes and the use of natural resources, especially water resources.
\end{abstract}

Keywords: Energy Sources, Energy Efficiency, Thermoelectric, Hydroelectric.

\section{EFICIÊNCIA ENERGÉTICA NO AMAZONAS: A ALTERNATIVA SOLAR}

\begin{abstract}
RESUMO
$\mathrm{O}$ atual artigo tem por objetivo correlacionar a utilização de duas fontes de energia (termoelétrica e hidrelétrica) mais utilizadas no estado do Amazonas com os efeitos ambientais provenientes de sua geração e elucidar a energia solar como chave da eficiência energética e fonte de energia limpa e sustentável. Este trabalho trata-se de uma pesquisa bibliográfica com fins descritivos, apresenta como delimitação as usinas termoelétricas e hidrelétricas do Amazonas. É possível observar na apresentação de seus resultados os impactos ambientais causados pela geração de energia elétrica que são preocupantes e que medidas de curto prazo devem ser tomadas. Por fim, as considerações finais desvelam a necessidade de adaptação do sistema energético do Amazonas às energias renováveis, em especial a solar que apresenta grande potencial na região, porém ainda pouco explorada, tal adaptação já é verificada em países desenvolvidos, levando em consideração as mudanças climáticas e o uso dos recursos naturais, especialmente os hídricos.
\end{abstract}

Palavras-chave: Fontes de Energia, Eficiência Energética, Termoelétrica, Hidrelétrica.

\section{INTRODUÇÃO}

A eficiência energética é a utilização racional de energia, consistindo na utilização de modo eficiente a energia para alcançar determinado resultado. De modo literal sua definição baseia-se na relação entre a quantidade de energia empregada em uma atividade e aquela disponibilizada para sua realização. Utilizada no atendimento de nossas necessidades básicas como a locomoção, alimentação e manutenção da vida, podemos dizer que a energia é fundamental para que possamos suprir tais necessidades. 
Dentre todos os seres vivos, o homem é que mais depende da energia em suas diversas formas, pois desenvolveu ao longo da história, máquinas, usos e costumes que precisam, cada vez mais, de energia, principalmente a elétrica.

A crescente preocupação com as questões relacionadas ao impacto ambiental levaram países a buscar o desenvolvimento e a inserção de tecnologias de energias renováveis como base energética. Um dos fatores que levaram a esta preocupação foram: o forte desenvolvimento industrial, os elevados preços dos combustíveis tradicionais, tais como o petróleo e também a limitação dos combustíveis fósseis [1].

São várias as fontes que podem ser utilizadas como solução para este problema, em especial no Estado do Amazonas e uma destas fontes é a energia solar, tendo em vista que a região norte do Brasil possui um dos maiores índices de incidência solar no território brasileiro, fazendo com que assim esteja apta para receber investimentos para a instalação de usinas solares fotovoltáicas [2].

Voltando o olhar para o Brasil é possível observar seu grande potencial energético, no entanto as empresas que utilizam esses potenciais são bem variadas. As usinas de geração de energia elétrica consistem nas hidrelétricas, pequenas centrais elétricas, termoelétricas e nucleares.

O uso desmedido dos recursos hidráulicos pode acarretar em inundações de áreas florestais; sítios arqueológicos; áreas urbanas e rurais; fragmentação de ecossistemas; e conflitos sociais devido à transferência de comunidades para outras regiões, para evitar a inundação de suas residências [2].

O objetivo deste trabalho é correlacionar o uso dessas fontes de energia no Amazonas (termoelétricas e hidrelétricas) com os impactos ambientais decorrentes da geração de energia elétrica e apresentar a energia solar como forma de solução para o sistema atual. O que se refere aos meios de investigação classifica-se como pesquisa bibliográfica. Nesse tipo de pesquisa, há um estudo sistematizado desenvolvido com base em material publicado em livros, revistas, jornais, redes eletrônicas, isto é, material acessível ao público em geral [3].

A pesquisa classifica-se como descritiva, pois é uma forma de evidenciar particularidades de uma determinada população ou de determinado fenômeno ou evento, podendo também elucidar correlações entre variáveis e definir sua origem, não tendo compromisso de explicar os fenômenos que descreve, embora sirva de base para tal explicação [3].

O universo deste estudo foi composto pelas instituições geradoras e distribuidoras de energia elétrica, classificadas como fontes renováveis (hidrelétricas) e fontes não renováveis (termoelétricas). A delimitação do todo envolveu as principais usinas termoelétricas e a hidrelétrica de Balbina, como fontes geradoras de energia para o Estado, abordando seus impactos ambientais e a implantação de pequenas usinas solares no interior do Amazonas. Os tópicos desenvolvidos neste trabalho foram: (1) geração e distribuição de energia no estado do Amazonas; (2) impactos ambientais causados pelas termoelétricas e hidrelétricas; e (3) implantação de pequenas usinas de energia solar para comunidades ribeirinhas.

\section{REVISÃO BIBLIOGRÁFICA}

\section{II.1 GERAÇÃO E DISTRIBUIÇÃO DE ENERGIA NO AMAZONAS}

O modo mais comum de utilizar os recursos hídricos de acordo com é por meio das usinas hidrelétricas de grande porte, para suprimento da indústria e das grandes cidades [4]. As usinas hidráulicas utilizam as águas em altas quedas e com volumosos cursos, de grandes estruturas construídas na forma de barragens, conforme ilustrado na figura 1 , esse método exige com bastante frequência da alteração do curso dos rios, o que acaba ocasionando áreas alagadas.

\section{Usina Hidrelétrica}

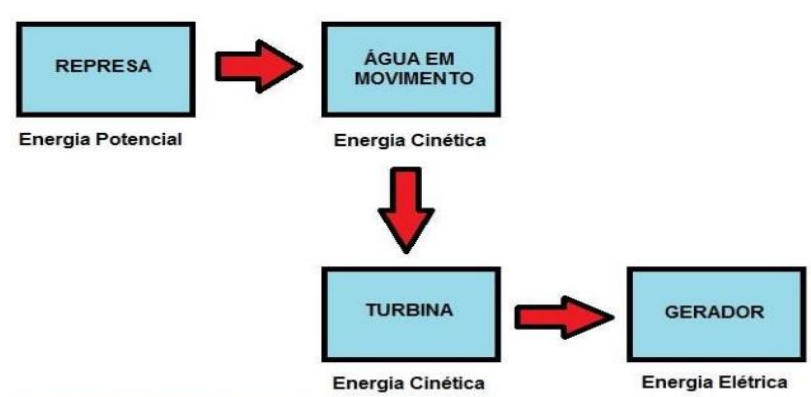

Figura 01 - Processo de geração de energia elétrica na usina hidrelétrica.

Fonte: $<$ https://pt.slideshare.net/joaopauloluna/aula-3transformao-de-energia/5>. Acesso em: 20 Mar. 2019.

Esse recurso aplicado para a produção de energia elétrica é o método elementar na atual matriz energética brasileira, contudo ainda em expansão na Região Amazônica pelo fato de disputas entre Organizações Não Governamentais (ONG's) que visam a defesa do meio ambiente e governos que intercedem com interesses no crescimento e desenvolvimento econômico do país enfatizando um política de interligação da nação através de redes de energia.

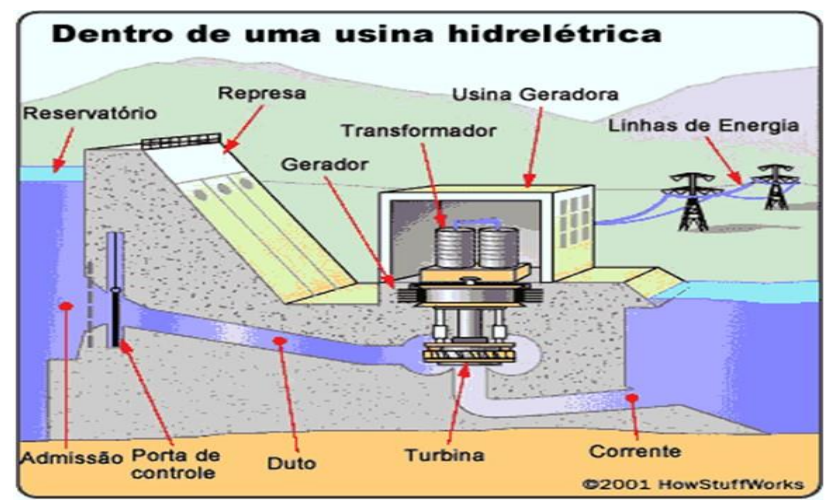

Figura 02 - Funcionamento de uma hidrelétrica.

Fonte: <http://eletronicapro.blogspot.com/2010/11/componentesde-uma-usina-hidreletrica.html>. Acesso: 20 Mar. 2019.

A estrutura do sistema centralizado de geração, distribuição e transmissão de eletricidade no Brasil foi definida de maneira que pudesse servir grandes consumidores agroindustriais rurais, por ainda ser um país agrícola e por estes estarem localizados próximo da malha rodoviária. Esta arquitetura, por razões de demanda, geográficas e custos, exclui pequenas populações de diversas origens sociais da Região Amazônica.

Agricultores familiares, extrativistas e pescadores de comunidades ribeirinhas, quilombolas e indígenas são as populações que quase sempre estão abaixo da linha de pobreza e por este fator podem encontrar na eletricidade meios para alavancar suas vocações produtivas e seu bem-estar social [6].

\section{II.2 IMPACTOS AMBIENTAIS CAUSADOS PELAS TERMOELÉTRICAS E HIDRELÉTRICAS}

Existem grupos de um lado que se posicionam contra as obras, alegando não considerarem satisfatórios os impactos físicos socioambientais e do outro lado aqueles que são a favor 
exclusivamente neste caso se trata do governo que defendem que as usinas são indispensáveis para a segurança energética e ao atendimento à constante crescente da demanda nacional, contribuindo para uma autosuficiência da rede de energia renovável, com um baixo custo, livre de emissões de gases e poluentes [7].

Ao contrário das usinas termelétricas, as usinas hidrelétricas utilizam-se de recursos renováveis e de baixo custo, as águas. Mas suas estruturações não devem estar voltadas apenas para o interesse econômico e o retorno financeiro que essa atividade resultará para o país. É preciso ater-se para os inúmeros impactos irreversíveis, os quais a atividade é responsável por ocasionar.

Em velocidade incontrolável, o cenário mundial está apresentando mudanças relacionadas a três fatores nesse início de século: o meio ambiente, a energia e a economia global. Suas interligações se apresentam nas seguintes características: a razão meio ambiente e energia já são conhecidos pela população, pelo fato das grandes emissões de poluentes, causando o efeito estufa e o aquecimento global, que acontece através da queima de combustíveis fósseis. O ultimo fator é o econômico que necessitará somente do tempo para se ter uma certeza dos efeitos da crise financeira mundial sobre o setor energético e com mais dificuldade de se saber sobre o meio ambiente. Tendo em vista que a exclusiva certeza é que todos os três serão afetados de forma negativa.

Em grande parte de sua extensão, o estado do Amazonas possui termelétricas, que em seu processo de geração de energia elétrica e utilizam como matéria-prima o combustível principal e os combustíveis auxiliares, que são a a água, o ar o ar e produtos químicos, gerando assim uma gama de efluentes com um grande potencial nocivo ao meio ambiente. Mas segundo Vichi e Mansor o principal impacto está nas emissões aéreas, de partículas de matéria e gases, resultado da queima do combustível[8].

De um ecossistema insubstituível, as florestas nativas são diretamente afetadas. Para serem formadas demandam anos e quando sofrem esse tipo de ação negativa, são destruídas em horas ou até mesmo em minutos. Existem muitos casos em que esse processo impossibilita o solo de tornar fértil novamente, pois as enxurradas levam o solo e o subsolo, deixando existente tão somente as rochas.

\section{II.3 IMPLANTAÇÃO DE PEQUENAS USINAS DE ENERGIA SOLAR PARA COMUNIDADES RIBEIRINHAS}

Em função da utilização de novas energias renováveis o estudo da viabilidade de implantação do sistema de energia solar tem estimável relevância, considerando que a grande maioria das fontes utilizadas não são renováveis, detalhe que faz bastante diferença levando em consideração a colaboração para a degradação ambiental.

Os pontos positivos da energia solar são: por ser abundante renovável e ainda não poluir, o que levou a Gomes afirmar que seria a solução ideal para suprir eletricamente as áreas remotas de difícil acesso ao fornecimento de energia elétrica convencional [9]. A energia solar fotovoltaica é uma fonte ilimitada de energia e está disponível em todos os lugares do mundo, uma vez que se torna importante salientar que o processo não depende do calor, o que diminuiria seu rendimento, tal fator pôde ser comprovado na prática de acordo com Palz células solares foram instaladas no Pólo Sul: não só funcionaram muito bem, mas geraram mais potência do que se comparado a climas temperados [10].

Um dos benefícios do uso da energia solar fotovoltaica é que ela é uma fonte ilimitada de energia e está disponível em todos os lugares do mundo. Não gera gases e ruídos nocivos e seu estabelecimento se torna fácil praticamente não carecendo de revisão. De acordo com Wanderley e Campos os módulos duram aproximadamente 30 anos e ainda podendo ser gerada em áreas afastadas das grandes cidades [11].

Em um breve levantamento na busca de lojas em Manaus que comercializem painéis fotovoltaicos, pudemos encontrar: Amazonas Energia Solar Ltda.; Aggreko Brasil Energia Ltda.; Protesystem Engenharia; Q Luz Solar; Soenergy Sistemas Internacionais de Energia; e Operadores de Energia Ltda. O custo dos painéis ainda é elevado, pelo fato de que ainda não ser fabricado no Brasil.

Para se ter ideia, segundo dados levantado pela Empresa Brasil de Comunicação - EBC, o custo de geração da energia solar está na média de $\mathrm{R} \$ 450$, enquanto a média do preço pelas outras fontes custa $\mathrm{R} \$ 150$ reais por MWh (Mega-Watt/hora), considerando uma produção em grande escala comparado a uma usina hidrelétrica ou termelétrica. Um painel com potência de 140 W chega a custar, em média, de $\mathrm{R} \$ 600$ a $\mathrm{R} \$ 700$ reais, para se ter um chuveiro elétrico com energia solar o investimento gira em torno de $\mathrm{R} \$ 4.000$ reais e para uma residência inteira está na faixa de $\mathrm{R} \$ 20.000$ reais.

Um sistema fotovoltáico conforme a figura 3 é composto pelos seguintes itens:

- Painel fotovoltaico: são placas desenvolvidas para converter diretamente a energia da luz do sol em energia elétrica, sob a forma de corrente contínua;

- Baterias: onde a energia é armazenada para uso posterior quando não há luz solar;

- Controlador de carga: controla a entrada e saída de energia das baterias;

- Inversor de corrente: uma vez que painéis produzem corrente contínua e a maior parte dos eletrodomésticos consomem corrente alternada;

- Sistema de apoio: quando a energia solar for insuficiente, um pequeno gerador a diesel, por exemplo.

A figura 3 a seguir ilustra de forma mais prática este sistema:

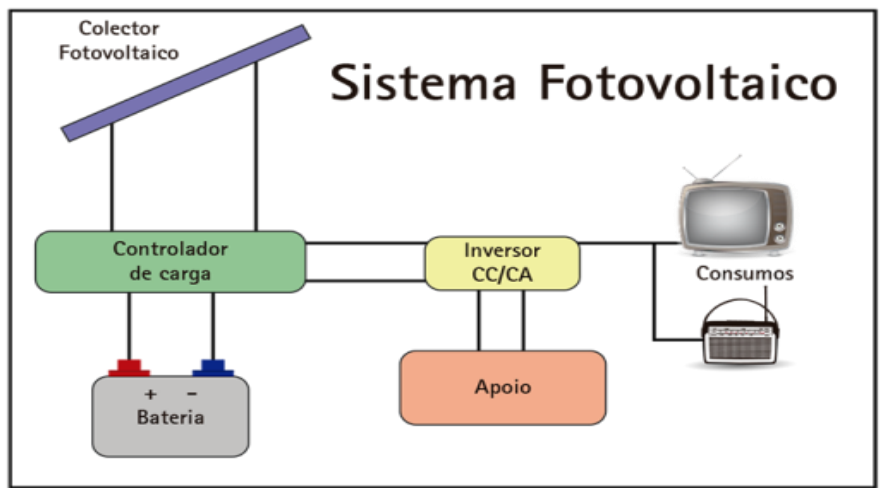

Figura 03 - Componentes de um sistema fotovoltaico.

Fonte: $<$ http://www.energiasrenovaveis.com/DetalheConceitos.asp ?ID_conteudo=44\&ID_area=8\&ID_sub_area=26>. Acesso: 25 Mar. 2019.

O Programa Luz para todos do Governo Federal através da Eletrobras Amazonas Energia é hoje um programa presente em algumas comunidades isoladas no Amazonas. O projeto implantou 12 miniusinas fotovoltaicas nas localidades de São Sebastião do Rio Preto (Autazes), Terra Nova (Barcelos), Nossa Senhora do Carmo (Beruri), Mourão e Santo Antônio (Eirunepé), Nossa Senhora de Nazaré, Santa Luzia, Santa Maria e São José (Maués), Aracari, Bom Jesus do Puduari e Sobrado (Novo Airão).

O custo de implantação de uma miniusina fotovoltaica é o mais elevado, comparado com a hidrelétrica é $30 \%$ a mais e com a 
termoelétrica é 1/5 mais elevado. Porém, é vantajoso na operação de geração de energia elétrica e a área de implantação utiliza um terreno de 25,00 X 25,00m, sendo que para novos projetos está previsto um terreno de $50 \times 50 \mathrm{~m}$ [12].

\section{MATERIAIS E MÉTODOS}

A priori foram definidos em três tópicos os principais conceitos relativos à eficiência energética no estado do amazonas propondo a energia solar como principal alternativa, expondo de que modo ocorre a geração e distribuição de energia no Estado do Amazonas, quais os impactos ambientais causados pelas termoelétricas e hidrelétricas que são as fontes mais utilizadas na região de acordo com o levantamento da pesquisa e por fim apresenta a implantação de pequenas usinas de energia solar para comunidades ribeirinhas que hoje em dia é uma realidade e se encontram presentes em 12 comunidades isoladas no Amazonas.

A base de dados para obtenção dos artigos analisados foi o Google Acadêmico e Scielo. As pesquisas foram realizadas a partir da análise de diferentes artigos científicos recentes como fontes de pesquisas, publicados no período compreendido entre 2012 a 2019.

\section{RESULTADOS}

Esta pesquisa buscou elucidar os aspectos principais relacionados à utilização de duas fontes de energia mais usufruídas no estado do Amazonas com os efeitos ambientais provenientes de sua geração e evidenciar a energia solar como chave da eficiência energética e fonte de energia limpa e sustentável.

Deste modo, observou-se que um projeto de eficiência energética define ações em determinada operação, visando primordialmente a redução de custos com consumo de insumos energéticos e hídricos, apresentando sugestões de viabilidade técnico-econômica de implantação, incluindo as especificações técnicas, equipamentos, materiais, serviços e as implantações propriamente ditas, além do gerenciamento do projeto e a gestão dos resultados após o término das intervenções [14].

A previsão do Governo Federal é de que as de que as termoelétricas sejam desativadas em função da interligação ao Sistema Integrado Nacional, através da linha Tucuruí, o que mostra a atual situação de mudança do sistema energético do Estado do Amazonas. Contudo, segundo o levantamento da Absolar, o Amazonas é um dos estados que menos investe em energia solar no Brasil. Atualmente, o País produz 124,7 megawatts (mW), enquanto o Amazonas tem potência de apenas $0,055 \mathrm{~mW}$, o que representa $0,04 \%$ da geração de energia distribuída em todo o País.

De acordo com Melo o Amazonas ainda não desenvolveu o sistema, ficando muito abaixo do potencial que possui. O Brasil possui um dos melhores níveis de radiação solar na atmosfera. Sendo assim segundo a autora esse recurso poderia ser melhor aproveitado[15]. E segundo Rodrigo Sauai, presidente da Absolar ( Associação Brasileira de Energia Solar ), na região Norte, o Amazonas é o $5^{\circ}$ em geração de energia solar, ficando atrás dos estados de Rondônia, Tocantins, Pará e Amapá. Roraima é o único que ainda não possui nenhum sistema de geração de energia solar fotovoltaica.

Sobre a implantação e geração de energia elétrica através da energia solar segundo a Eletrobras Distribuição Amazonas, os sistemas de energia solar fotovoltaicas devem ser interligados à rede da concessionária. $\mathrm{O}$ procedimento para que os clientes possam comercializar a energia gerada funciona da seguinte forma: em caso de uso excedente gerado pelo cliente, o quilowatt-hora vira créditos em faturas subsequentes, no limite de até 60 meses para uso dos créditos gerados. A Eletrobras explicou que mesmo gerando e produzindo toda a energia, o cliente precisa pagar o custo de conexão com a rede elétrica, que varia por tipo de ligação (baixa e média tensão). Para utilizar placas fotovoltaicas é necessário um parecer de acesso e aprovação de projeto, para que o sistema possa operar em sincronismo com o fornecimento de energia elétrica da distribuidora.

\section{CONCLUSÃO}

Neste estudo se fez uma revisão teórica sobre Eficiência Energética no Amazonas propondo a energia solar como fonte alternativa. Uma forma de aproveitamento desta energia é através da conversão direta em energia elétrica por meio dos painéis fotovoltaicos. Foram comparadas diversas características construtivas e de rendimento das células fotovoltaicas. Como sua eficiência de conversão não é elevada, e como o ângulo de incidência da luz é variável ao longo do dia e das estações do ano, a aplicação de sistemas para o posicionamento dinâmico de painéis fotovoltaicos pode ser uma solução para levar o rendimento ao máximo. Foi explanado de que forma acontece a geração de energia e sua distribuição por todo o Estado, demonstrando de maneira explicativa quais os impactos ambientais gerados pelo uso continuo das termoelétricas e hidrelétricas, apresentou a realidade de algumas comunidades ribeirinhas que atualmente foram comtempladas em um projeto em parceria do governo com a Eletrobrás.

A tecnologia existente hoje para painéis solares fotovoltaicos ainda encontra-se em desenvolvimento, tanto por conta de seu custo elevado como de sua baixa eficiência, o que acaba por abrir caminho para que sistemas automatizados possam complementar eficiência ao processo de conversão direta da energia solar em elétrica a fim de expandir os horizontes desta tecnologia e num futuro próximo diminuir a níveis toleráveis ou até eliminar a dependência dos combustíveis fósseis que trazem efeitos nocivos para o Estado do Amazonas.

\section{REFERÊNCIAS}

[1] Tazvinga, H.; Xiaohua, X.; Jiangfeng; Z. Minimum cost solution of photovoltaic-diesel-battery hybrid power systems for remote consumers. Solar Energy. 96: 292-299. 2013.

[2] SOUZA, M. P. de. Análise da viabilidade de utilização da energia solar como fonte alternativa de geração de energia na cidade de Manaus. [dissertação] Universidade Federal Do Amazonas, Faculdade De Tecnologia, Programa De PósGraduação Em Engenharia De Produção, 2016.

[3] Brasil. Ministério do Meio Ambiente. Governança ambiental: energia. Disponível em: <http://www.mma.gov.br/governancaambiental/portal-nacional-delicenciamento-

ambiental/licenciamento-

ambiental/atualidadesempreendimentos/item/8322-energia>.

Acesso: 20 Mai. 2019.

[4] Kripka, Rosana Maria Luvezute; Scheller, Morgana; Bonotto, Danusa Lara. Pesquisa documental: considerações sobre conceitos e características na pesquisa qualitativa. Atas CIAIQ2015, v. 2, 2015.

[5] PINHO, João Tavares, et al. Sistemas híbridos.Brasília: Ministério de Minas e Energia, 2008. 
[6] FRATE, Claudio Albuquerque. Brasil Junior, Antonio Cesar Pinho. Tecnologias hidrocinética e de gaseificação: requisitos de hibridismo e aplicação em comunidades amazônicas remotas. Revista Universo \& Extensão. Vol. 1, No. 1. Belém: UFPA, 2013. Disponível em: <http://www.revistaeletronica.ufpa.br/index.ph>.

[7] Coelho, Maria Célia Nunes, et al. Questão energética na Amazônia: disputa em torno de um novo padrão de desenvolvimento econômico e social. Novos cadernos NAEA. Vol.13, No. 2. Belém: UFPA, 2010. Disponível em: <http://www.periodicos.ufpa.br/index.php/ncn/article/viewArticle /475>. Acesso: Mar. 2014.

[8] Vichi, Flavio Maron. MANSOR, Maria Teresa Castilho. Energia, meio ambiente e economia: o Brasil no contexto mundial. Quimica nova. Vol. 32, No. 3. São Paulo: 2009. Disponível em: $<$ http://www.scientificcircle.com/pt/50983/energia-meioambiente-economia-brasil-contexto-mundial/>. Acesso: 10 Mar. 2019.

[9] Gomes, Caio Peixoto. Energia solar: utilização como fonte de energia alternativa. Revista Bolsista de Valor. Vol. 2, No. 1. Rio de Janeiro: Essentia Editora, 2012. Disponível em: $<$ http://www.essentiaeditora.iff.edu.br/index.php/BolsistaDeValor /article/view/2411>. Acesso: Abr. 2014.

[10] Palz, W. Energia solar e fonte alternativas. Hermus, 2002.

[11]Wanderley, Augusto César Fialho. Campos, Antonio Luiz P. Siqueira. Perspectivas de inserção da energia solar fotovoltaica na geração de energia elétrica no Rio Grande do Norte. Revista Holos. Ano 29, Vol. 3. Natal: IFRN, 2013. Disponível em: <http://www2.ifrn.edu.br/ojs/index.php/HOLOS/article/view/149 3>. Acesso: 29 Abr. 2019.

[12] Teixeira, Alexandre de Almeida. Carvalho, Matheus Costa. Leite, Leonardo Henrique de Melo. Análise de viabilidade para a implantação do sistema de energia solar residencial. Revista Exacta. Vol. 4, No. 3. Belo Horizonte: UniBH, 2011. Disponível em: <http://revistas.unibh.br/index.php/dcet/article/view/689>.

Acesso: abr. 2019.

[13] Lima, F. da C.; Borges, J. T. Gestão energética no Amazonas: a alternativa solar. T\&C Amazonia, 2014. Disponível em: < http://tecamazonia.com.br/artigo-gestao-energetica-no-amazonasa-alternativa-solar/>. Acesso em: 15 Abr. 2019.

[14] ABESCO- Associação Brasileira das Empresas de Serviço de Conservação de Energia. Disponível em: http://www.abesco.com.br/pt/como-funciona-um-projeto-deeficiencia-energetica/>. Acesso em: 15 Mar. 2019.

[15] Melo, K. Amazonas não explora potencial de geração de energia solar, diz associação. Disponível em: $<$ http://www.acritica.com/channels/governo/news/amazonas-naoexplora-potencial-de-geracao-de-energia-solar-diz-associacao >.

Acesso em: 20 Abr. 2019. 